\title{
Possible Treatment for Children with ASD: A Review
}

\author{
Berenice Domíguez $^{1}$, Joel Flores ${ }^{2}$, Rita Trinidad Rodríguez ${ }^{3}$ \\ Assistant Professor, Communications and Electronic Engineering Department (ICE), ESIME-ZAC, IPN, \\ Mexico City, Mexico ${ }^{1}$ \\ Professor, Communications and Electronic Engineering Department (ICE), ESIME-ZAC, IPN, Mexico City, Mexico ${ }^{2-3}$
}

\begin{abstract}
In this work, the recommended treatments for children with ASD are retaken, from the point of view of sensory stimulation, through occupational therapy for Mexican children, since it is proposed to ensure that a treatment by auditory stimulation can support or interact with a musical instrument as a game for children to receive motor, sensory, cognitive and emotional stimulation, based on the fact that auditory stimulation has been shown to be an excellent aid in stress and anxiety treatments.
\end{abstract}

Keywords: Autism Spectrum Disorder (ASD), Diagnostic and Statistical Manual of Mental Disorders (DSM), Sensory stimulation, Occupational therapy, Sensory integration.

\section{INTRODUCTION}

The National Institute of Statistics, Geography and Informatics (INEGI) published in 2013 that, in 2010, 5 million 739 thousand 270 people have some type of disability, which represents $5 \%$ of the total population [10]. Within this group of people, one out of every 112 children has Autism Spectrum Disorder (ASD) in Mexico [1]. This sector of the population lacks government support for its proper care and also has difficulties in accessing institutions dedicated to the care of the aforementioned disorder (of the budget allocated to health, $2 \%$ is allocated to mental health and practically not to autism); Due to the great demand and in many cases when the patient's turn finally arrives on the waiting list, it is too late for the therapies to be used correctly; whereas it is proven that early intervention improves the results in the rehabilitation process of children with this disorder [2]. It should be noted that adequate treatment for ASD must be multidisciplinary and for many parents it is not affordable to have the services of a pediatric neurologist, nutritionist, specialized therapists, etc. [3].

\section{DESCRIPTION}

The American Psychiatric Association APA, published on May 18, 2013 the Diagnostic and Statistical Manual of Mental Disorders (DSM), in whose fifth edition, Autism Spectrum Disorder (ASD) is defined as the persistent difficulty in the development of the process of socialization, along with a restricted pattern of behaviors and interests, including sensory restrictions. The classic concept of ASD has varied greatly since its original descriptions described by Leo Kanner (1943) who defines it as "an innate autistic alteration of affective contact" and Hans Asperger (1944). ASD is a set of symptoms due to central nervous system dysfunction with varying degrees of intensity [4]. ASD is a complex neurobiological disorder that is associated with rigid routines and repetitive behaviors. ASD is four times more likely in boys than in girls. Parents usually detect certain unusual characteristics in their children, on average at 3 years of age compared to other children of the same age, since from this age there is an alteration in their development; the main affectations are manifested in social and communicative behavior. The most recent censuses indicate that ASD is even more common than childhood cancer, diabetes or AIDS. In Mexico, until not more than 20 years ago, talking about specialized centers for the detection and treatment of ASD was almost impossible, mainly because it was a little-known disorder and, consequently, there were a very small number of specialists and spaces for its detection and treatment [5].

According to the DSM-5, the criteria for diagnosing ASD are classified as follows:

A. Persistent deficiencies in communication and social interaction across multiple contexts, as manifested by the following current or past symptoms.

A.1 Deficiencies in socio-emotional reciprocity; for example:

- $\quad$ Abnormal social approach.

- $\quad$ Failure in normal two-way conversation.

- $\quad$ Decrease in shared interests, emotions, or affections. 


\section{International Advanced Research Journal in Science, Engineering and Technology}

Vol. 7, Issue 12, December 2020

\section{DOI 10.17148/IARJSET.2020.71206}

- $\quad$ Failure to initiate or respond to social interactions.

A.2 Deficiencies in non-verbal communicative behaviors used in social interaction; for example:

- $\quad$ Poorly integrated verbal and non-verbal communication.

- $\quad$ Abnormality in eye contact and body language.

- $\quad$ Poor understanding and use of gestures.

- $\quad$ Total lack of facial expression and non-verbal communication.

A.3 Deficiencies in the development, maintenance and understanding of relationships; for example:

- $\quad$ Difficulty adjusting behavior to various social contexts.

- $\quad$ Difficulty sharing imaginative play or making friends.

- $\quad$ Lack of interest in other people.

B. Repetitive and restricted patterns of behavior, activities, and interests.

B.1 Stereotyped or repetitive movements, use of objects or speech; for example:

- Simple motor stereotypies.

- $\quad$ Alignment of toys.

- $\quad$ Change of place of objects.

- Echolalia

- Idiosyncratic phrases.

B.2 Insistence on monotony, excessive inflexibility to routines, or ritualized patterns of verbal and non-verbal behavior; for example:

- $\quad$ High anguish before small changes.

- Difficulties with transitions.

- $\quad$ Rigid Thought Patterns.

- Greeting rituals.

- $\quad$ Need to always follow the same route or eat the same foods every day.

B.3 Very restrictive and fixed interests that are abnormal in terms of intensity and focus of interest; for example:

- $\quad$ Strong attachment or high concern for unusual objects.

- Overly circumscribed and persistent interests.

B.4 Hiccups or hypersensitivity to sensory stimuli or unusual interest in sensory aspects of the environment; for example:

- $\quad$ Apparent indifference to pain / temperature.

- $\quad$ Adverse response to specific sounds and textures.

- $\quad$ Smelling or excessively touching objects

- Visual fascination with lights or movements.

C. Symptoms have to manifest in the early developmental period. However, they may not be fully revealed until societal demands exceed their limited capabilities. These symptoms may be masked by strategies learned later in life.

D. Symptoms cause significant clinical deterioration in social, occupational, or other areas important to normal functioning.

E. The disorders are not better explained by an intellectual disability or by a global delay in development.

In view of the above, it can be commented that the diagnosis of ASD is based on behavior, and the interpretation of an altered, absent or delayed behavior, which depends on a solid base of clinical knowledge. However, and as mentioned previously, the first phase consists of detection, where the observations made by the parents about the child's development will be of great help for its diagnosis. It will then be important to pay attention to the following warning signs according to the age of the child [6].

First 6 months of life:

He/She doesn't show anticipatory posture when picking him up.

$\mathrm{He} / \mathrm{She}$ doesn't babble.

Lack of social smile.

Eye contact absent.

Fix your eyes on light stimuli. Irritability.

He/She has palmar grasp but does not look at the object.

Sleep disorder.

From 6 to 12 months of life:

Disregard for parents.

He/She doesn't take part in games of social interaction.

He/She doesn't respond or anticipate.

$\mathrm{He} / \mathrm{She}$ doesn't imitate sounds or gestures. 
He/She isn't interested in offered toys.

Shows fascination with their hands and feet.

Smell or suck on objects.

Sleep disorder.

Second year of life:

$\mathrm{He} / \mathrm{She}$ may start the march late.

He/She isn't interested in children his age.

He/She doesn't signal with the intention of teaching or sharing.

$\mathrm{He} / \mathrm{She}$ doesn't share attention or interest with others.

He/She doesn't develop symbolic play.

Irritable, difficult to console.

Weird postures and strange movements of the hands and feet.

Inappropriate emotional reactions.

Sleep disorder.

Third year of life:

Limited interpersonal interest.

Poor eye contact.

Stare blankly or in an unusual way.

He/She doesn't develop speech or is scarce, echolalia.

He/She doesn't like changes, gets irritated easily.

Tantrums and assaults.

Self-stimulation.

Manipulative dexterity.

Hiccups or hyperactivity.

Sleep disorder [7].

As the observations of the parents are evident, the severity of the problem can be determined in clinical terms. The DSM5 indicates that from the identification of the characteristics that the patient possesses of the points A, B, C, D and E mentioned above, levels of severity of the Autism Spectrum Disorder can be established [6], as shown in Table 1.

TABLE 1. SEVERITY LEVELS OF AUTISM SPECTRUM DISORDER

\begin{tabular}{|c|c|c|}
\hline $\begin{array}{c}\text { Severity } \\
\text { level }\end{array}$ & Social communication & $\begin{array}{c}\text { Restricted interests and repetitive } \\
\text { behavior }\end{array}$ \\
\hline $\begin{array}{l}\text { Level 1. } \\
\text { Requires } \\
\text { support }\end{array}$ & $\begin{array}{l}\text { Without supports, social communication difficulties } \\
\text { cause obvious disturbances. Shows difficulties initiating } \\
\text { social interactions and offers clear examples of atypical } \\
\text { or failed responses to the social openings of others. Your } \\
\text { interest in social interaction may appear to be } \\
\text { diminished. For example, a person who is able to speak } \\
\text { in full sentences and engage in communication but who } \\
\text { sometimes fails to flow back and forth in conversations } \\
\text { and whose attempts to make friends are atypical and } \\
\text { generally unsuccessful. }\end{array}$ & $\begin{array}{l}\text { Behavioral inflexibility causes significant } \\
\text { interference with performance in one or } \\
\text { more contexts. Organizational and planning } \\
\text { problems hamper independence. }\end{array}$ \\
\hline $\begin{array}{l}\text { Level 2. } \\
\text { Requires } \\
\text { support } \\
\text { substantial }\end{array}$ & $\begin{array}{l}\text { Marked deficits in verbal and non-verbal } \\
\text { communication skills; social deficits are apparent even } \\
\text { with support; initiate a limited number of social } \\
\text { interactions; and they respond in an atypical or reduced } \\
\text { way to the relationship attempts of others. For example, } \\
\text { a person who speaks in simple sentences, whose ability } \\
\text { to interact is limited to restricted interests, and who } \\
\text { exhibits atypical non-verbal behaviors. }\end{array}$ & $\begin{array}{l}\text { Inflexible behavior, difficulties in coping } \\
\text { with change, or other restricted / repetitive } \\
\text { behaviors, appear often enough to be } \\
\text { obvious to an untrained observer and } \\
\text { interfere with functioning in a variety of } \\
\text { contexts. Great discomfort or difficulty in } \\
\text { changing the focus of interest or behavior. }\end{array}$ \\
\hline $\begin{array}{l}\text { Level } 3 . \\
\text { Requires } \\
\text { support } \\
\text { very } \\
\text { substantial }\end{array}$ & $\begin{array}{l}\text { Severe deficits in verbal and non-verbal social } \\
\text { communication skills that cause severe disturbances in } \\
\text { functioning, initiates very few interactions, and } \\
\text { responds minimally to the relationship attempts of } \\
\text { others. For example, a person with very few intelligible } \\
\text { words who rarely initiates social interactions, and when } \\
\text { he does, he makes unusual approaches solely to satisfy }\end{array}$ & $\begin{array}{l}\text { Behavioral inflexibility, extreme difficulty } \\
\text { coping with changes, or other restricted / } \\
\text { repetitive behaviors, markedly interfere } \\
\text { with functioning in all spheres. Great } \\
\text { discomfort or difficulty in changing the } \\
\text { focus of interest or behavior. }\end{array}$ \\
\hline
\end{tabular}



approaches.

\section{Treatment of ASD.}

Some researchers classify ASD treatments into different categories, as shown in Fig. 1. Each category focuses on one type of treatment or a specific group of symptoms and behaviors that are being addressed.

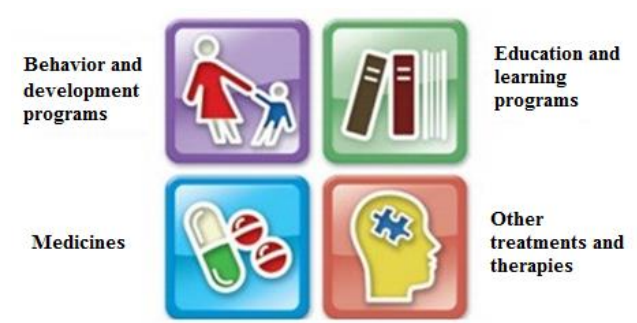

Fig. 1 Classification of ASD treatments

Because each child with an ASD may have different types of symptoms, the family may have to choose from the available treatments, therapies, and programs, based on the child's needs.

\section{Behavior and development programs}

These programs address: social skills, attention, sleep, play, anxiety, interaction with parents, difficult behaviors, and other activities. "Early Intensive Behavioral Intervention" programs use specially trained clinicians who work with parents and young children for up to 25 hours per week. Early intensive behavioral intervention programs can last from 12 weeks to 3 years.

\section{Education and learning programs}

These programs are offered in schools or other educational centers. They focus on learning and reasoning skills and "whole life" approaches. Each school or school district can give its program a different name, but many of these are based on the TEACCH method. Programs like TEACCH use visual aids and organize the classroom in a way that facilitates the performance of the child with ASD. Other programs operate according to the classroom or center and use Applied Behavioral Analysis (ABA) strategies, such as positive reinforcement.

\section{Medicines}

- $\quad$ Antipsychotics: Risperidone and Aripiprazole.

- $\quad$ Serotonin reuptake inhibitors or SRIs (antidepressants).

- $\quad$ Stimulants and other medications to treat hyperactivity.

- $\quad$ Secretin. This medicine is used to treat digestion problems, but some researchers think that it may also be helpful in children with ASD.

- $\quad$ Chelation. This treatment uses substances that remove heavy metals from the body, which some consider to cause ASD.

\section{Other treatments and therapies}

Other types of treatments or therapies that have been used in children with ASD are [8]:

- Speech and language therapy.

- Music therapy.

- Occupational therapy.

- $\quad$ Acupuncture.

- Vitamins and mineral supplements.

- $\quad$ Massage therapy.

- $\quad$ Communication system with exchange of images.

- $\quad$ Receptive prelinguistic teaching in a natural environment. 


\section{Sensory stimulation}

Sensory stimulation is a very practical and effective tool in occupational therapy and especially in the care of people with disabilities and the elderly with cognitive impairment, because it helps them train the mind and also psychomotor skills, through visual, auditory, tactile, olfactory and gustatory stimulus. From its origin, sensory stimulation has become an exemplary instrument to treat people with disabilities, since through its use a great evolution of learning and a better relationship with the world around them is achieved. Along these lines, multi-sensory rooms emerge, which are interactive spaces designed to stimulate the senses and generate experiences that help users to give meaning to the sensations they perceive. Through lighting, aromas, music and sounds, textures, etc., an atmosphere of calm, security and protection is recreated that invites exploration and play [9].

\section{Sensory integration}

Dr. Jean Ayres, an American occupational therapist, defined Sensory Integration as: "the neurological process that organizes sensation from our own body and from the environment." In other words, when a person presents challenges in sensory integration, it generates great difficulty in adapting to the environment that surrounds them and the demands it represents. Sensory integration activities for children with ASD help to:

- $\quad$ The correct daily functioning of the child.

- Their intellectual, social, and emotional development.

- Your development of positive self-esteem.

- Have your body and mind ready to learn.

- Generate positive interactions with the world around you.

- $\quad$ Go through the stages of normal development.

The variety of sensory stimulation activities is endless. Some of the most basic, popular, fun, and proven activities include [10]:

\section{a) High impact activities}

These activities are useful for children who usually bump, jump, leg constantly and can never seem to be calm. A strong stimulus can help them calm down. The premise behind these activities is to help your students receive a stimulation in muscles and joints in the most appropriate way, to be able to regulate their bodies. Some of these activities include: pushing, pulling, weighted objects, jumping, bouncing, rocking, swinging, squeezing, riding a bike, digging, and playing with sand.

\section{b) Play with textures}

Playing with different materials gives them essential and fun experiences while experiencing a tactile stimulus necessary for their development. Materials such as:

- $\quad$ Rub gently with a soft bristle brush on your body.

- Massage into hands with scent lotion.

- $\quad$ To paint with the fingers.

- $\quad$ Hide small objects, such as different seeds, rice, beans, lentils, etc.

- $\quad$ Play with shaving cream, baby oil, gel, flour, cornstarch

- $\mathrm{h}$, etc.

- $\quad$ Play with clay or sand.

- Use different fabrics.

\section{c) Vestibular stimulation}

Children need to move. For some it is difficult because they may be afraid, while for others the movement they may have during the day is never enough. Here are some ideas for these types of activities:

- $\quad$ Pool jumper or trampoline.

- Swings

- $\quad$ Rocking toys, such as a rocking horse or a seesaw.

- $\quad$ Ride on toys.

- $\quad$ Skateboards.

- Therapeutic balls. 


\section{International Advanced Research Journal in Science, Engineering and Technology}

Vol. 7, Issue 12, December 2020

\section{DOI 10.17148/IARJSET.2020.71206}

\section{d) Sensory toys}

Sensory toys can be found anywhere. There are also a number of ways to turn any toy into a sensory one. Here are some examples:

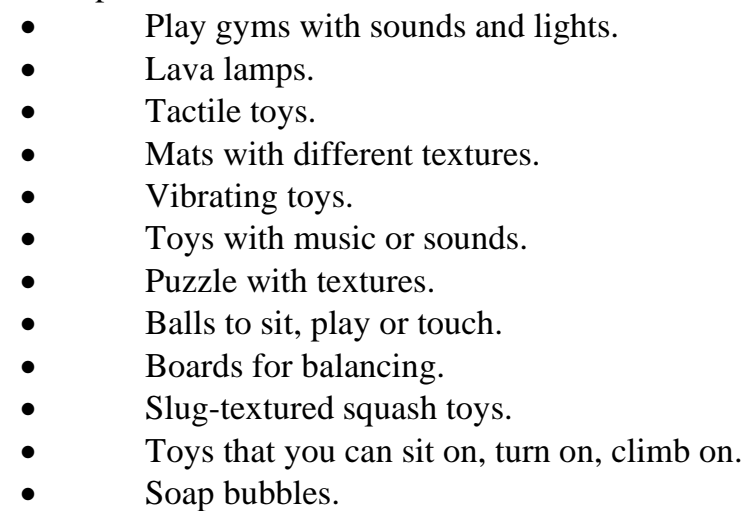

\section{III.RESULTS}

The realization of this theoretical framework on ASD, helped justify the use of an alternative tool through the implementation of a musical instrument, such is the case of a mat-type electronic keyboard; Since music is known to act positively at the neuronal level, the English Nordoff Robbins method, created after 17 years of collaboration with Paul Nordoff and Clive Robbins, has shown great benefits for children with developmental disorders, through therapy with music [11], [12]. A prototype of an electronic keyboard was developed with certain characteristics (sounds, textures and colors) that, when interacting with the instrument as a game, can be an alternative tool to improve the lifestyle they lead. However, field tests are pending (due to Covid-19) to observe the benefits of this prototype to the sector of the child population in Mexico that lives under the condition of Autism Spectrum Disorder.

\section{IV.CONCLUSION}

Although each child is different and ASD can present in various manifestations, music is a method to enhance aspects of the development of the child with ASD. Using music as a therapy tool can facilitate aspects such as learning skills at a social level, stimulate the understanding of various aspects of language, encourage the desire to communicate, offer a space for self-expression and help reduce the repetition of phrases or words. Mental health is essential in people, and paradoxically, it is the one that receives the least attention and it is our job to maintain it, and although there is no cure for autism, there are already many alternatives to include these children because it is also their right.

\section{REFERENCES}

[1]. F. Méndez. (2018) UNAM Global homepage. [Online]. Available: http://www.unamglobal.unam.mx/?p=25999

[2]. (2018) TELETON website. [Online]. Available: https://www .teleton . org/home/noticia/Que-es-el-Autismo.pdf

[3]. INEGI. (2018) Disability in Mexico homepage. [Online]. Available: http://cuentame.inegi.org.mx/poblacion/discapacidad. aspx?tema $=\mathrm{P}$

[4]. (2019) Society of Psychiatrics and Neurology of Children and Adolescents website. [Online]. Available: https : // www . camara . cl/pdf.aspx?prm ID=112506\&prmTIPO=DOCUMENTOCOMISION

[5]. G. Olivera . (2019) Mexican Clinic of Autism and Developmental Alterations A.C. homepage. [Online]. Available: http:// revistarayuela.ednica.org.mx /sites/default/files/2.pdf

[6]. R. Palomo. (2019)Homepage on TDSM-5: The new classification of ASD. [Online]. Available: http://apacu.info/wpcontent/uploads/2014/10/Nueva-clasificaci $\% 5 \mathrm{C} \% \mathrm{C} 3 \% 5 \mathrm{C} \% \mathrm{~B} 3 n-D S M V$.pdf

[7]. M. Schönstedt and A. Moyano. "Foundations of early intervention in children with autism spectrum disorders"., Chilean Journal of Pediatrics., vol. 2, pp. 126-131, 2015.

[8]. (2019) Agency for Healthcare Research y Quality homepage. [Online]. Available: https://effectivehealthcare.ahrq.gov/topics/autismupdate/espanol

[9]. Social and Health Balance of Dependency and Disability. (2019) Treatments for children with autism spectrum disorder homepage. [online]. Available: https://www.balancesociosanitario.com/Salas-multisensoriales-aplicadas-a-la-estimulacion_a867.html

[10]. Children's TELETON System. "Sensory Integration”.,TELETONJoumal,vol. 10, pp. 2-12, 2016.

[11]. S. Ferguson. (2018) UNICEF USA BrandVoice: New UNICEF Music Therapy Program Is Helping Syrian Refugee Children Heal homepage. [Online]. Available: https://www. forbes .com/sites/unicefusa/2018/06/21/a-new - unicef- music-therapy-program-ishelping-syrian-refugee-children-heal/\#7f28d5cc4f84

[12]. V. Muñoz. (2018) Mexican Institute of Humanist Music Therapy homepage. [Online]. Available: https://www.musicoterapias.com/ Musicoterapia-humanista.html 
International Advanced Research Journal in Science, Engineering and Technology

Vol. 7, Issue 12, December 2020

DOI 10.17148/IARJSET.2020.71206

\section{BIOGRAPHY}

Berenice Domínguez Márquez received her B.Sc. in electronics and communications engineering from ESIME Zacatenco IPN, Mexico, in 2019. Currently she is an assistant professor at the Department of Electronics and Communications engineering in ESIME Zacatenco. She has been a volunteer in projects for the conservation of the environment and is a commercial speaker. Her research interests are in bioacoustics.

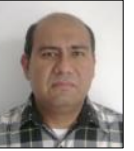

Joel Flores Martínez received his B.Sc. in electronics and communications engineering from ESIME Zacatenco IPN, Mexico, in 1997 and M.Sc. degree in Bioelectronics from CINVESTAV IPN, Mexico in 2000. Currently he is a professor at the Department of Electronics and Communications engineering in ESIME Zacatenco. His research interests are in acoustics and biomedical engineering.

Rita Trinidad Rodríguez Márquez received her B.Sc. in electric engineering from ESIME Zacatenco IPN, Mexico, in 1995. Currently she is a teacher at the Department of Electronics and Communications engineering. 